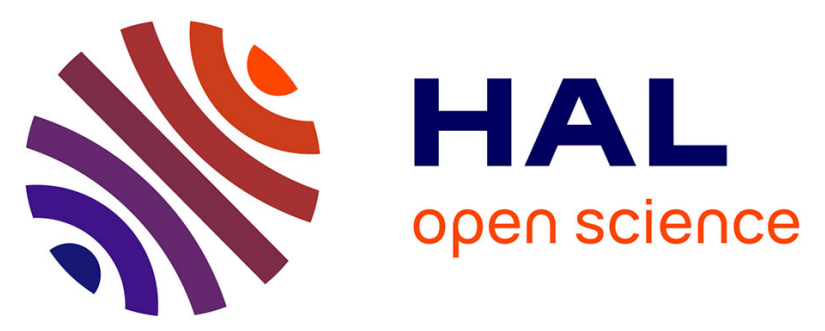

\title{
Influence of social deprivation and remoteness on the likelihood of sphincter amputation for rectal cancer: a high-resolution population-based study
}

Nathan Dolet, Véronique Bouvier, Yassine Eid, Alexandre Thobie, Annabel Boyer, Aurore Haffreingue, Marine Renier, Guy Launoy, Arnaud Alves, O. Dejardin

\section{To cite this version:}

Nathan Dolet, Véronique Bouvier, Yassine Eid, Alexandre Thobie, Annabel Boyer, et al.. Influence of social deprivation and remoteness on the likelihood of sphincter amputation for rectal cancer: a high-resolution population-based study. International Journal of Colorectal Disease, 2019, 34 (5), pp.927-931. 10.1007/s00384-019-03272-8 . inserm-02100771

\section{HAL Id: inserm-02100771 https://www.hal.inserm.fr/inserm-02100771}

Submitted on 16 Apr 2019

HAL is a multi-disciplinary open access archive for the deposit and dissemination of scientific research documents, whether they are published or not. The documents may come from teaching and research institutions in France or abroad, or from public or private research centers.
L'archive ouverte pluridisciplinaire HAL, est destinée au dépôt et à la diffusion de documents scientifiques de niveau recherche, publiés ou non, émanant des établissements d'enseignement et de recherche français ou étrangers, des laboratoires publics ou privés. 
Influence of social deprivation and remoteness on the likelihood of sphincter amputation for rectal cancer: a high-resolution population-based study

Authors

DOLET.N ${ }^{a, b, e}$, BOUVIER.V ${ }^{a, b, c}$, EID.Y., ${ }^{a, b, d}$, THOBIE.A $A^{a, b, d} ;$ BOYER.A $^{a, b}$, HAFFREINGUE.A a,e, RENIER.M ${ }^{b}$, LAUNOY.G ${ }^{a, b, c}$, ALVES.A ${ }^{a, b, d}$, DEJARDIN.O $O^{a, b}$

Author's affiliation

${ }^{a}$ Department of Research, Caen University Hospital, Caen, France

b "ANTICIPE" U1086 INSERM-UCN, TEAM “Ligue Contre le Cancer", François

Baclesse Cancer Center, CAEN, France

${ }^{\mathrm{C}}$ Calvados Digestive Cancer Registry, Caen, France

${ }^{d}$ Department of Digestive Surgery, Caen University Hospital, Caen, France

e Department of Pediatric Surgery, Caen University Hospital, Caen, France

\section{Corresponding author}

Dr Dejardin Olivier, Pôle de Recherche CHU Caen; Centre François Baclesse; Avenue du General Harris - BP 5026; 14076 Caen Cedex 05; France

Tel +33 (0)231458623

Fax $+33(0) 231530852$

Mail: olivier.dejardin@unicaen.fr

Word count: 1658

Keywords: Health care accessibility; rectal cancer; surgery; sphincter amputation; deprivation;

social environment

The manuscript has not been published previously. Even if population-based studies were not explicitly mentioned, our article is in accordance with RECORD guidelines for observational study.

All authors have read and approved the manuscript. We have no conflict of interest to declare 


\section{Abstract}

Background: Medical care in rectal cancer is subject to social inequality. According to the last French guidelines, a 1-cm distal margin below the lower pole of the rectal tumor is now considered sufficient. This extends the limits of the current sphincter preservation gold standard. Like for others innovative technics, the dissemination of such technics is often subject to social and geographical inequalities. The objective was to analyze whether sphincter preservation in rectal cancer is subject to social or geographical inequality.

Methods: The odds of sphincter preservation was modeled by logistic regression among the 1453 patients in the Calvados digestive cancer registry between 01/01/1997 and 31/12/2016, by examining some of the variables that could influence it: social inequalities and geographical remoteness, sex, age and stage.

Results: $69.4 \%$ of the population received sphincter preservation. Patients in the more deprived quintiles had a significantly higher probability of having sphincter amputation (OR=1.469 (1.046-2.064). This result was no longer significant after adjustment on stage and travel-time. There was a dose-effect pattern of geographical remoteness on likelihood of sphincter preservation with a progressive increase in OR between patients living the nearest and the furthest from the reference center ( $p$-trend $=0.0178)$.

Conclusion: This study shows that the probability of receiving sphincter preservation is influenced by the social environment and strongly influenced by remoteness. Although management guidelines have had a huge impact on the rates of sphincter preservation, they have not reduced the influence of the social and geographical environment on sphincter preservation 


\section{Introduction}

Outcomes of rectal cancer patients have improved considerably thanks to optimal surgery by total mesorectal excision (TME) in conjunction with multidisciplinary team management and selective multimodal therapy (i.e., neo-adjuvant chemo-radiotherapy). Surgical techniques have extended the limits of sphincter preservation without impairing the oncological prognosis [1]. This progress has resulted in more patients receiving sphincterpreserving surgery (SPS) [2]. This improved coverage has allowed up to $80 \%$ of patients with rectal cancer to receive SPS.

Like for others innovative technics, the dissemination of such technics is often subject to social and geographical inequalities. Most studies dealing with social inequalities and in the surgical management of lower-tract digestive cancer have mainly focused on colon cancer[3]. Even if rectal cancer was less deeply studied, some studies found a correlation between variables representative of social status and sphincter amputation $[4,5]$.

Concerning geographical remoteness, evidences are weak and highly depend on health care system organization. Remoteness was reported as highly associated with disparities in management and survival for patients diagnosed with cancer in US or France $[6,7]$ whilst this association was not significant in England [8]. To date, the geographical inequality in rectal cancer care has received little attention.

This study explored the relative influence of social and geographical inequalities on the outcome of rectal cancer to determine whether socioeconomic deprivation and/or geographic remoteness are independent predictors of non-restorative rectal cancer surgery. 


\section{Methods}

\section{Population}

Calvados is a French department in Normandy with an estimated population of 694,660 in 2016. Calvados has one teaching hospital and 12 other public and private centers. All patients with a rectal adenocarcinoma diagnosed in Calvados, registered in the Calvados digestive cancer registry between 01/01/1997 and 31/12/2016 (C20 8140/3 in International Classification of Diseases for Oncology 3) and treated by curative surgery were included in the present study $(\mathrm{N}=1463)$ (Table 1$)$

\section{Treatment procedures}

The following data were extracted from the medical records of each patient in the registry: age at diagnosis; gender; timing and type of neoadjuvant radiotherapy and chemotherapy; sphincter-preserving surgery with or without stoma; abdomino-perineal excision; Hartmann's procedure; tumor, node, and/or metastasis stage by pathology report. When the procedure was not clear for sphincter status, we checked the report of the operation. Sphincter preservation was evaluated after the first surgery. Since reasons for no reestablishment were unknown, patients with stoma protection who did not have a reestablishment were classified as sphincter preservation. In the different models, risk of sphincter amputation was modeled. Since sphincter preservation is the gold standard, this class was chosen as the reference class.

\section{Socioeconomic status}

The European Deprivation Index (EDI) was used to assess the socioeconomic environment of each patient [9] and takes the French socio-economic situation into account. Patients are assigned to an IRIS (Ilots Regroupés pour l'Information Statistique) according to 
their address. The IRIS is the smallest geographical area for which there is a statistical evaluation to estimate social deprivation. Once the patient was attached to an IRIS, their EDI could be established. We used the national quintile of distribution of this EDI, quintile 1 representing patients who live in the most privileged areas.

\section{Travel time to reference care center}

Travel time was estimated with the patient's address and defined as the shortest time to travel by car to the reference care center (regardless of where the patient received care), i.e. Caen University Hospital. A Geographical Information System (ArcGIS $10.5^{\circledR}$ - Esri France) associated with a roadmap database (Navstreets ${ }^{\circledR}$, provided by HERE and Esri France) was used to estimate the travel time between the patient's residence and the reference care center. Travel time was estimated in minutes and divided into classes of $15 \mathrm{~min}$.

\section{Variables}

Classification of stage was based on the TNM edition 7. The stage without metastasis and invaded lymph node (stage 0 , stage I and stage II) was gathered. The stage III represent invaded lymph node $(\mathrm{N}+)$ and the stage IV metastasis $(\mathrm{M}+)$. Lymph node status was evaluated by pathology report. Metastasis was evaluated by radiological assessment before management. New recommendations on the management of rectal cancer were published by the French health authority on 01/02/2006 and include radiological assessment, neoadjuvant treatment, surgery, follow-up, and therapeutic advice for the surgical management of the sphincter. The change in care in this population became effective after 1 year so the reference data was $01 / 01 / 2007$ to analyze the impact of the new recommendations.

\section{Statistics}


The results were obtained with a logistic regression model. All variables were analyzed with a univariate model (Table 1 , model 0 ). Four models were then established: model 1 with age and gender, model 2 with stage added to model 1, model 3 with the new recommendations added to model 2 and model 4 with geographical deprivation added to model 3. Sex and age variables were forced into the multivariate models despite a non-significant $p$ value, since we decided that they should be considered based on the literature and for clinical reasons.

Since only few missing values (reported in table 1) were present, we have used the listwise deletion method.

\section{Results}

\section{Influence of deprivation on the likelihood of sphincter amputation}

In the univariate model (Table 1, model 0), sphincter amputation was associated with deprivation. Patients in the more deprived quintiles had a significantly higher probability of having sphincter amputation than (OR=1.469 (1.046-2.064); $p$ value 0.0266$)$ compared to the other patients. After adjustment on age and sex, the association between deprivation and the likelihood of sphincter amputation was still significant (adjusted Odds-ratio: ORa=1.413 (1.0031.992); $p=0,048 ;$ Table 1, model M1). After adjustment on stage, deprived patients had a greater likelihood of having a sphincter amputation but, even if the magnitude of the effect remained stable, the $p$ value was no longer significant for this last model (ORa=1.368 (0.9671.936), $\mathrm{p}=0.076$, Table 1 model $\mathrm{M} 2$ ). The adjustment on recommendation period had no effect on the association (Table 1, Model M3). Finally, after adjustment on travel-time, deprivation was not associated with the likelihood of sphincter amputation (ORa=1.276 (0.892-1.825), $\mathrm{p}=0,181$, table 1 , model M4). Travel times to reference care centre was the variable that had the greatest impact in the successive models with a net loss of significance of the $p$-value and a decrease in the effect. 


\section{Influence of remoteness on the likelihood of sphincter amputation}

In univariate analysis, patients with a travel time to the reference center greater than 30 min had significantly more sphincter amputation than those who lived within 15 min of it. Patient with a travel time between 30 and $44 \mathrm{~min}$ had an OR=1.422 (IC $95 \%$ [1.068-1.893]) and those who lived more than $45 \mathrm{~min}$ away had an OR=1.637 (IC95 \% [1.082-2.479]). Travel time was linearly significantly associated with sphincter amputation (Table 1 , model 0 ).

The multivariate model investigating geographic deprivation did not find any variable that fully explained the effect observed in the univariate model (Table 1, model 4). There was a dose-effect pattern of geographical remoteness on likelihood of sphincter preservation with a progressive increase in OR between patients living the nearest and the furthest from the reference center (respectively $\mathrm{OR}=1.06(0.80-1.45) ; \mathrm{OR}=1.36(1.02-1.87)$ and $\mathrm{OR}=1.46$ (0.94-1.48) for each $15 \mathrm{~min}$ increase of travel-times, $\mathrm{p}$-trend $=0.0178)$. 


\section{Discussion}

The main finding of our study is that deprived patients and those living further from the center had less access to sphincter preservation, the current gold standard for the curative management of rectal cancer. Our study also highlighted that, although management guidelines have had a huge impact on the rates of sphincter preservation, they have not reduced the influence of the social and geographical environment on sphincter preservation

Concerning the influence of material deprivation, our results showed that the influence of material deprivation is partly explained by stage at presentation. However, the influence of stage on the likelihood of having a sphincter amputation could not fully explained the influence of deprivation. The influence of travel-times seems to be crucial in the explanation of the relationship between deprivation and the likelihood of having a sphincter amputation

Since neither clinical variables nor treatment variables nor deprivation could explain the influence of remoteness on sphincter amputation, geographical remoteness seems to be an independent prognostic factor of the likelihood of receiving sphincter preservation. The "doseeffect" pattern between sphincter amputation and travel time is a striking fact, even in an area for which the reference care center is located in the centroid of the area. Consequently, the influence of remoteness might be more important in more rural department.

It was not possible to obtain information on the surgeon who had performed the surgery, so we could not assess the influence of surgical volume on sphincter preservation. Indeed, since patients are treated in the closer hospital [10] for numerous reasons (mean age at diagnosis, proximity to family, health care pathways...), the explanation of our results by a 
lower use of sphincter preservation in non-specialized hospitals is attractive. Future studies should take this variable into account in order to reveal the effect of surgeon and hospital.

Data regarding the impact of socio-economic status on rectal cancer are to date scarce. European data mainly come from the National Bowel Cancer Project study [5], and from the Swedish rectal cancer registry. The British administrative database initially suggested an association between socioeconomic deprivation and abdominoperineal excision for rectal cancer. However, given the lack of data on demographic factors and tumor characteristics, it was not possible to demonstrate an independent relation between socio-economic deprivation and non-restorative rectal cancer surgery [5]. Results from Swedish rectal cancer registry, based on 7433 patients suggested an association with socioeconomic factors [11].

A systematic literature review showed a negative impact of stoma on quality of life in colorectal cancer [12]. Even if it is less clear in rectal cancer due to the complications after surgery with sphincter preservation, the latter remains the gold standard when feasible. In conclusion, our study demonstrates that the probability of receiving sphincter preservation is highly influenced by the patient's social and geographical environment. Therefore, health care in France requires a new form of organization, where high-volume surgeons should practice surgery in low-volume hospitals to reduce the geographical gap in management and survival. The impact of this recommendation should be monitored over the coming years.

\section{Acknowledgements}

We thank the Mapinmed and the Ligue Nationale Contre le Cancer for their help. The authors declare no conflict of interest. 
Table 1: Influence of clinical and demographic variables on the probability of sphincter amputation for patients diagnosed in Calvados between 1997 and 2016 after successive adjustments (logistic regressions)

\begin{tabular}{|c|c|c|c|c|c|c|c|c|c|c|c|c|c|c|c|c|c|c|c|c|c|c|}
\hline \multirow[b]{3}{*}{ EDI } & \multirow{3}{*}{$\frac{S{ }^{*}}{N}$} & \multirow{3}{*}{$\frac{\text { No SP* }}{\mathrm{N}}$} & \multicolumn{4}{|c|}{ Univariate analysis } & \multicolumn{4}{|c|}{$\mathrm{M} 1: \mathrm{M} 0+$ sexe and Age } & \multicolumn{4}{|c|}{ M2 : M1 + Stage } & \multicolumn{4}{|c|}{ M3 : M2 + Period } & \multicolumn{4}{|c|}{ M4 : M3 + travel time } \\
\hline & & & \multirow[t]{2}{*}{$\mathrm{OR}$} & \multicolumn{2}{|c|}{ IC } & \multirow{3}{*}{$\begin{array}{c}p \\
0,027\end{array}$} & \multirow{3}{*}{$\begin{array}{l}\text { OR } \\
1\end{array}$} & \multicolumn{2}{|c|}{ IC } & \multirow[t]{2}{*}{$\mathrm{p}$} & \multirow[t]{2}{*}{$\mathrm{OR}$} & \multirow{2}{*}{\multicolumn{2}{|c|}{ IC }} & \multirow[t]{2}{*}{$\mathrm{p}$} & \multirow[t]{2}{*}{ OR } & \multirow{2}{*}{\multicolumn{2}{|c|}{ IC }} & \multirow[t]{2}{*}{$\mathrm{p}$} & \multirow[t]{2}{*}{ OR } & \multirow{2}{*}{\multicolumn{2}{|c|}{ IC }} & \multirow[t]{2}{*}{$\mathrm{p}$} \\
\hline & & & & & & & & & & & & & & & & & & & & & & \\
\hline Quintile 1 & 50 & 157 & 1 & & & & & & & 0,048 & 1 & & & 0,077 & 1 & & & 0,080 & 1 & & & 0,181 \\
\hline Quintile2+3+4+5 & 394 & 842 & 1,47 & 1,05 & 2,06 & & 1,41 & 1,00 & 1,99 & & 1,37 & 0,97 & 7,94 & & 1,37 & 0,96 & 1,95 & & 1,28 & 0,89 & 1,83 & \\
\hline Unknown & 4 & 16 & & & & & & & & & & & & & & & & & & & & \\
\hline \multicolumn{23}{|l|}{ Age } \\
\hline$<60$ years & 109 & 264 & 1 & & & 0,012 & 1 & & & 0,021 & 1 & & & 0,017 & 1 & & & 0,024 & 1 & & & 0,028 \\
\hline $60-69$ years & 97 & 300 & 0,76 & 0,55 & 1,05 & & 0,76 & 0,55 & 1,04 & & 0,80 & 0,57 & 1,11 & & 0,83 & 0,60 & 1,17 & & 0,83 & 0,60 & 1,16 & \\
\hline $70-79$ years & 162 & 305 & 1,28 & 0,95 & 1,72 & & 1,26 & 0,93 & 1,69 & & 1,27 & 0,94 & 1,72 & & 1,20 & 0,88 & 1,64 & & 1,21 & 0,89 & 1,65 & \\
\hline$>80$ Years & 80 & 146 & 1,30 & 0,91 & 1,85 & & 1,29 & 0,90 & 1,84 & & 1,35 & 0,94 & 1,94 & & 1,40 & 0,97 & 2,03 & & 1,38 & 0,95 & 2,00 & \\
\hline Gender & & & & & & & & & & & & & & & & & & & & & & \\
\hline Men & 275 & 622 & 1 & & & 0.9702 & 1 & & & 0,449 & 1 & & & 0,593 & 1 & & & 0,649 & 1 & & & 0,675 \\
\hline Women & 173 & 393 & 1,00 & 0,79 & 1,25 & & 0,91 & 0,72 & 1,16 & & 0,94 & 0,74 & 1,19 & & 0,95 & 0,74 & 1,21 & & 0,95 & 0,74 & 1,21 & \\
\hline Stage & & & & & & & & & & & & & & & & & & & & & & \\
\hline $1+2$ & 241 & 581 & 1 & & & 0,172 & & & & & 1 & & & 0,175 & 1 & & & 0,318 & 1 & & & 0,347 \\
\hline 3 vs $1+2$ & 120 & 236 & 1,23 & 0,94 & 1,60 & & & & & & 1,23 & 0,94 & 1,61 & & 1,19 & 0,90 & 1,56 & & 1,18 & 0,90 & 1,55 & \\
\hline 4 vs $1+2$ & 71 & 134 & 1,28 & 0,92 & 1,77 & & & & & & 1,28 & 0,92 & 1,78 & & 1,22 & 0,88 & 1,71 & & 1,21 & 0,87 & 1,70 & \\
\hline Unknown & 16 & 64 & & & & & & & & & & & & & & & & & & & & \\
\hline Period & & & & & & & & & & & & & & & & & & & & & & \\
\hline $\begin{array}{l}\text { before } \\
\text { recommandation }\end{array}$ & 293 & 479 & 1 & & & $<.0001$ & & & & & & & & & 1 & & & $<, 0001$ & 1 & & & $<, 0001$ \\
\hline after recommandation & 155 & 536 & 0,47 & 0,38 & 0,60 & & & & & & & & & & 0,47 & 0,37 & 0,59 & & 0,47 & 0,37 & 0,59 & \\
\hline Travel time & & & & & & & & & & & & & & & & & & & & & & \\
\hline$<15 \min$ & 139 & 376 & 1 & & & 0,003 & & & & & & & & & & & & & 1 & & & 0,018 \\
\hline $15-29 \mathrm{~min}$ & 130 & 310 & 1,13 & 0,86 & 1,51 & & & & & & & & & & & & & & 1,07 & 0,80 & 1,45 & \\
\hline $30-44 \mathrm{~min}$ & 133 & 253 & 1,42 & 1,07 & 1,89 & & & & & & & & & & & & & & 1,38 & 1,02 & 1,87 & \\
\hline$\geq 45 \mathrm{~min}$ & 46 & 76 & 1,64 & 1,08 & 2,48 & & & & & & & & & & & & & & 1,46 & 0,94 & 2,28 & \\
\hline Unknown & 1 & 16 & & & & & & & & & & & & & & & & & & & & \\
\hline
\end{tabular}

$\mathrm{Sp}:$ Sphincter preservation 


\section{Bibliography}

1. Lakkis Z, Manceau G, Bridoux V, et al (2017) Management of rectal cancer: the 2016 French guidelines. Colorectal Dis 19:115-122. https://doi.org/10.1111/codi.13550

2. Chau A, Maggiori L, Debove C, et al (2014) Toward the End of Abdominoperineal Resection for Rectal Cancer? An 8-Year Experience in 189 Consecutive Patients With Low Rectal Cancer: Ann Surg 260:801-806. https://doi.org/10.1097/SLA.0000000000000979

3. Aarts MJ, Lemmens VEPP, Willem $J$, et al Socioeconomic status and changing inequalities in colorectal cancer? A review of the associations with risk, treatment and outcome. Eur J Cancer 15:. https://doi.org/doi:10.1016/j.ejca.2010.04.026

4. Tilney H, Lovegrove RE, Smith JJ, et al (2009) The National Bowel Cancer Project: Social Deprivation Is an Independent Predictor of Nonrestorative Rectal Cancer Surgery. Dis Colon Rectum 52:1046-1053. https://doi.org/10.1007/DCR.0b013e3181a65f41

5. Smith JJ, Tilney HS, Heriot AG, et al (2006) Social deprivation and outcomes in colorectal cancer. Br J Surg 93:1123-1131. https://doi.org/10.1002/bjs.5357

6. Dejardin O, Jones AP, Rachet B, et al (2014) The influence of geographical access to health care and material deprivation on colorectal cancer survival: Evidence from France and Health Place 30C:36-44. https://doi.org/10.1016/j.healthplace.2014.08.002

7. Henry KA, Niu XL, Boscoe FP (2009) Geographic disparities in colorectal cancer survival. Int J Health Geogr 8:13. https://doi.org/10.1186/1476-072x-8-48

8. Jones AP, Haynes R, Sauerzapf V, et al (2008) Travel times to health care and survival from cancers in Northern England. Eur J Cancer 44:269-74

9. Guillaume E, Pornet C, Dejardin O, et al (2016) Development of a cross-cultural deprivation index in five European countries. J Epidemiol Community Health 70:493499. https://doi.org/10.1136/jech-2015-205729

10. Dejardin O, Bouvier AM, Herbert C, et al (2005) Social and geographic disparities in access to reference care site for patients with colorectal cancer in France. Br J Cancer 92:1842-5. https://doi.org/10.1038/sj.bjc.6602571

11. Olsson LI, Granström F, Påhlman L (2010) Sphincter preservation in rectal cancer is associated with patients' socioeconomic status. $\mathrm{Br}$ J Surg 97:1572-1581. https://doi.org/10.1002/bjs.7157

12. Vonk-Klaassen SM, de Vocht HM, den Ouden MEM, et al (2016) Ostomy-related problems and their impact on quality of life of colorectal cancer ostomates: a systematic review. Qual Life Res 25:125-133. https://doi.org/10.1007/s11136-0151050-3 